\title{
THE ACUTE AND LONG-TERM OCULAR EFFECTS OF ACCELERATED HYPERTENSION: A CLINICAL AND ELECTROPHYSIOLOGICAL STUDY
}

\author{
S. J. TALKS ${ }^{1,2}$, P. GOOD ${ }^{2}$, C. G. CLOUGH ${ }^{3}$, D. G. BEEVERS ${ }^{3}$ and P. M. DODSON ${ }^{1,2}$ \\ Birmingham
}

\begin{abstract}
SUMMARY
Thirty-four patients with accelerated hypertension were clinically examined. The visual evoked potential (VEP) and electroretinogram (ERG) were recorded: acutely in 12 patients, being repeated in 7 patients up to 6 months later. In the remaining 22 patients these tests were performed 2-4 years after presentation. Visual acuity was $\leq 6 / 12$ in 22 of $68(32 \%)$ eyes at presentation and $\leq 6 / 12$ in 10 of $58(19 \%)$ eyes at follow-up. The cause of severest loss of vision appeared to be anterior ischaemic optic neuropathy, found in 3 cases. During the acute stage 11 patients $(92 \%)$ had abnormal VEPs and all had abnormal ERGs. The group mean P100 latency, of the 7 patients (14 eyes) seen acutely and followed up at 6 months, was $123.8 \mathrm{~ms}$ with significant recovery of latency $(p<0.005)$ to $110.9 \mathrm{~ms}$. The ERGs, however, remained reduced and delayed. In those patients recorded 2-4 years after their acute episode the VEP was abnormal in only 2 patients $(9 \%)$; group mean P100 latency was $109.1 \mathrm{~ms}$. However, 18 patients $(82 \%)$ had abnormal ERGs. We suggest that during the acute stage of accelerated hyertension there is a high incidence of ischaemic optic neuropathy that usually resolves but can cause a permanent anterior ischaemic optic neuropathy, in addition to vascular retinopathy that persists.
\end{abstract}

The effects of hypertension on the eye have long been recognised. In 1836, Bright $^{1}$ gave the first report of renal disease associated with visual disturbance. Mackenzie, ${ }^{2}$ reporting a case of Bright's disease, wrote that 'the heart, the brain and the organs of vision seem peculiarly liable to suffer from it', and that the deterioration of vision may vary 'from dimness up to total insensibility to sight'. With

From: ${ }^{1}$ Departments of Medicine and Ophthalmology, Birmingham Heartlands Hospital; ${ }^{2}$ Birmingham and Midland Eye Hospital; and ${ }^{3}$ University Department of Medicine, City Hospital, Birmingham, UK.

Correspondence to: Mr S. J. Talks, The Eye Hospital, Radcliffe Infirmary, Woodstock Road, Oxford OX2 6HE. UK. the invention of the ophthalmoscope in 1851 the causes of this disturbance could be described. ${ }^{3}$ Leibreich ${ }^{4}$ in 1859 , was the first to describe 'albuminuric retinitis' in Bright's disease. However, it was not until 1914, after the invention of the RivaRocci sphygmomanometer ${ }^{5}$ at the end of the nineteenth century, that Volhard and Fahr ${ }^{6}$ related the retinopathy to arterial hypertension.

It was then realised that the fundal appearance was associated with the severity of the hypertension and with the prognosis of the patient. In 1939 Keith et $a l .^{7}$ drew up a four-group grading system. Grade 3 (more recently called accelerated hypertension ${ }^{8}$ ) consisted of 'angiospastic retinitis', 'characterised especially by oedema, cotton wool patches, and haemorrhages in the retina superimposed on a combination of sclerotic and spastic lesions in the arterioles'. Grade 4 (malignant hypertension) had the same picture with disc oedema. This group of patients had the worse prognosis, with $79 \%$ dead within 1 year and only $1 \%$ surviving at 5 years. This classification is still used ${ }^{9}$ but more recently it has been found that there is little difference in the survival of patients with grade 3 or 4 hypertensive retinopathy. ${ }^{10.11}$ It has therefore been proposed that the two stages be classified together and called accelerated hypertension. . $^{2,13}$

The prognosis for patients with accelerated hypertension has greatly improved with the advent of effective hypertensive treatment. ${ }^{14,15}$ However, the condition is still serious. The 10 year survival of such patients was reported as $48 \%$ in a paper published in $1986,{ }^{11}$ but many centres now have 5 year survival data of $80 \%$, ${ }^{13}$ with a worse prognosis in patients with renal failure. With treatment, the damaging effect of hypertension is greatly reduced, but it is not all reversed. ${ }^{16}$ Retinopathy and disc swelling usually disappear within 6-12 months of the onset of antihypertensive therapy. ${ }^{17}$ However, retinal and optic nerve function may not return to normal 
because of infarction. ${ }^{18}$ Little has been written on the long-term effects of hypertension on ocular function. With increased survival, studies on this aspect are now appropriate.

The effects of hypertension on the eye can be divided into hypertensive retinopathy, choroidopathy and neuropathy. ${ }^{19,20}$ There has been debate about whether disc swelling in accelerated hypertension is due to raised intracranial pressure or to ischaemia. $^{21} \mathrm{We}$ felt electrophysiological measurements would be useful to examine these processes and are not aware that this has been done before.

\section{SUBJECTS AND METHODS}

A total of 34 patients with accelerated hypertension were studied: 20 males, 14 females (age range 17-80 years, mean age 47.5 years). These patients were referred to the authors over an 8 year period for the management of accelerated hypertension. The patients were studied prospectively; however, not all the patients had electrophysiological tests acutely as will be explained. The diagnosis was made on finding grade III or IV hypertensive retinopathy (Keith, Wagener, Barker classification: grade III, narrowing of retinal arterioles, arteriovenous nipping, cotton wool spots, haemorrhages, exudates, retinal oedema; grade IV, the same changes plus disc swelling) in combination with hypertension and

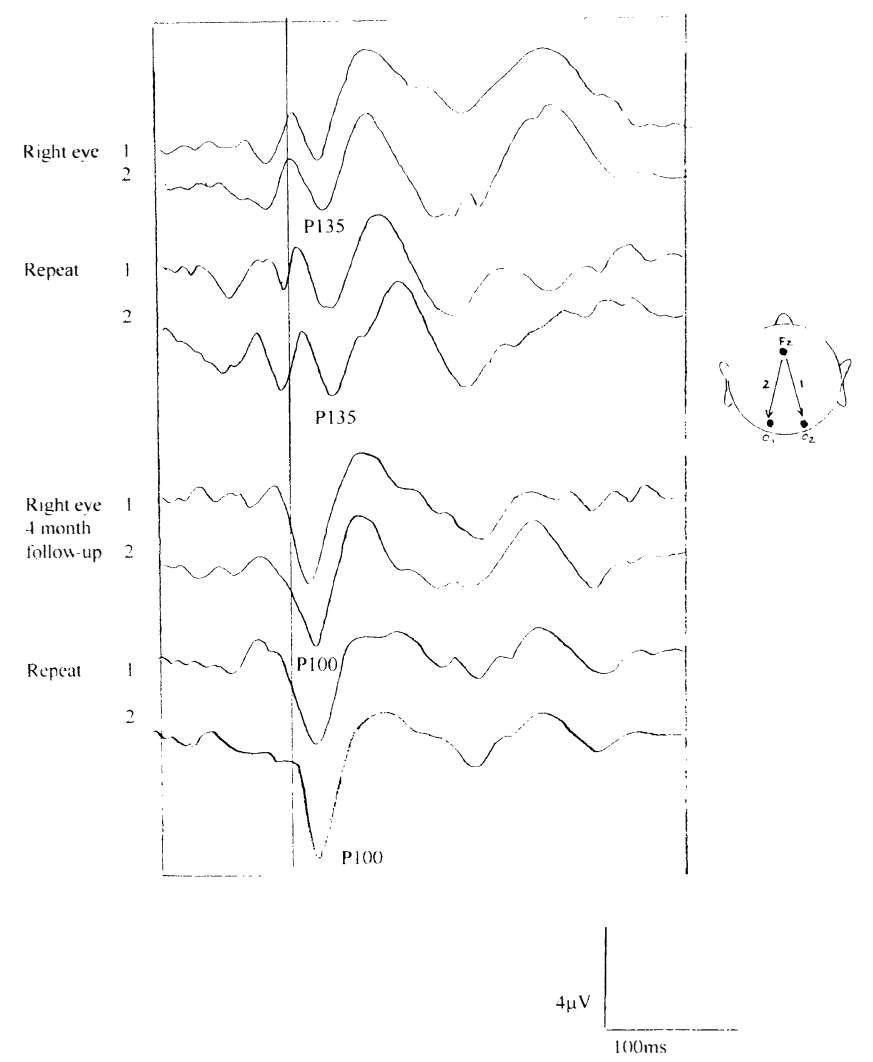

Fig. 1. Patient 1, from Table II (female, aged 19 years). The right $V E P$, during the acute phase, showing a paramacular response to 50 minute checks. Repeat traces are shown. This resolved 4 months later. proteinuria. In the majority the blood pressure was greater than 200/140 $\mathrm{mmHg}$. An exact level of blood pressure is not required for the diagnosis of accelerated hypertension. ${ }^{13}$ All had a clinical ocular examination at presentation, including pupil dilation as well as systemic examination and investigations, including urea and electrolytes, creatinine, chest radiograph and electrocardiogram (all were examined by the authors). Patients with ocular or neurological abnormalities not related to hypertension were excluded. All the patients had repeat clinical examinations at follow-up.

Twelve of the patients had electrophysiological and visual field measurements within a few days of their acute presentation. Seven of these were followed up for up to 6 months with repeat measurements. Twenty-two of the patients had electrophysiological and visual field measurements only 2-4 years after their initial presentation, but not at acute presentation.

The information recorded was: best corrected visual acuity; fundal appearance (this was documented by grading with the Keith, Wagener, Barker classification in both the acute and treated patients, plus by other features, such as optic atrophy, being recorded); Goldmann visual fields; pattern visual evoked potentials (VEP); flash electroretinograms (ERG). As this study was carried out over an 8 year

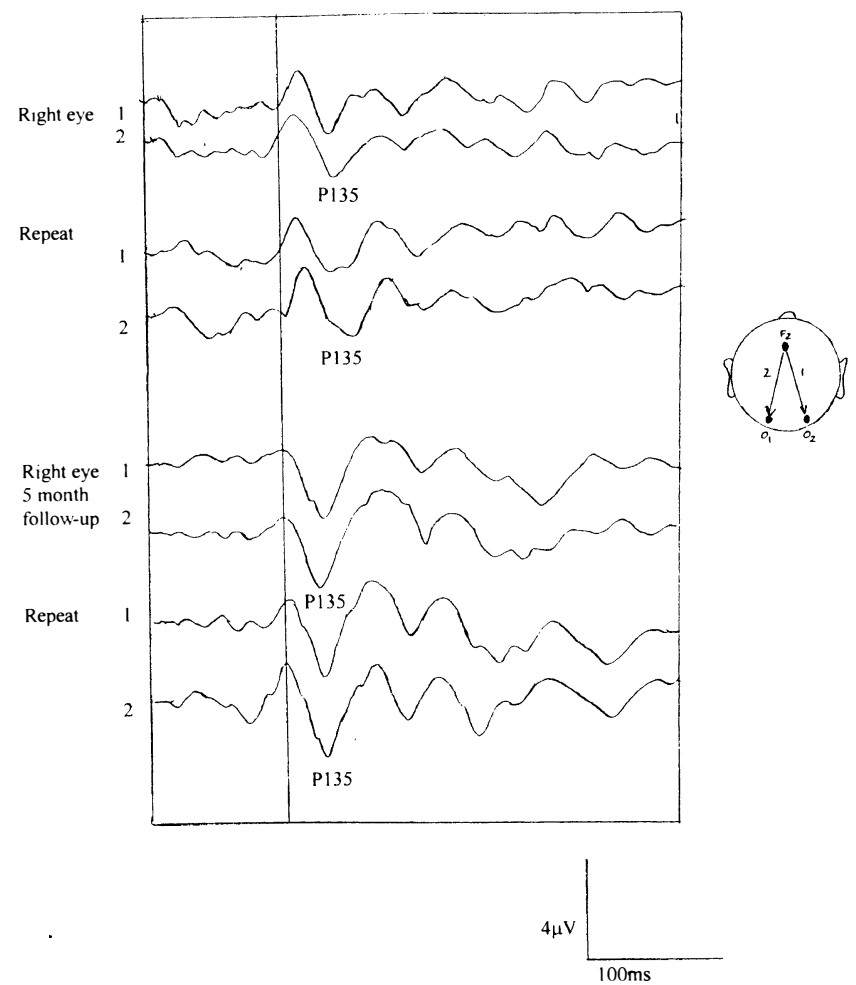

Fig. 2. Patient 5, from Table II (male, aged 27 years). Right VEP during the acute phase showing a paramacular (P135) response to 50 minute checks. Repeat traces are shown. This resolved 5 months later. The left eye (not illustrated) had a delayed low-amplitude response that did not resolve. 
period, only two of the more recently performed tests included pattern electroretinograms (PERG).

The VEP and ERG results were compared with 20 randomly selected controls. These were age- and sexmatched normotensive, normal subjects with no neurological or ophthalmic abnormality, selected from the electrophysiological department's control data base (mean age 43.8 years; 10 male, 10 female).

VEPs were obtained using a Nicolet $\mathrm{C} 4$ clinical averager. The stimulus consisted of a black and white checkerboard of $100 \%$ contrast reversing at $1.9 \mathrm{~Hz}$. The stimulus field was 14 degrees, and the check size was 50 minutes of arc subtended at the eye. A $\mathrm{Ag} / \mathrm{AgCl}$ electrode was located at positions $\mathrm{Fz}(10 / 20$ montage system) and referred to $\mathrm{Ag} / \mathrm{AgCl}$ electrodes positioned at 01 and 02 . The amplifier band-pass filter was set at $1-50 \mathrm{~Hz}$ and artefact rejection was set at $100 \mu \mathrm{V}$. No notch filtering was employed. For each recording sequence 40 averages were obtained, and this was repeated two times for responses falling within the normal range of amplitude and latency, and three times for abnormal responses.

The presence of PNP wave forms in pattern VEPs of patients with anterior ischaemic optic neuropathy (AION) has been previously described by Thompson et al., ${ }^{22}$ where the $\mathrm{P} 100$ macular response is replaced by a P135 paramacular response leaving a negative component at approximately $100 \mathrm{~ms}$. In Thompson's study all these VEPs were of low amplitude. To identify this wave form in our study we looked for a reproducible, low-amplitude positive-negative-positive response with the dominant positive at $>122 \mathrm{~ms}$ preceded by a consistent clearly defined negative component at $\geqslant 100 \mathrm{~ms}$. VEPs of normal amplitude but delayed without this positive-negative-positive wave form were considered to be a delayed P100 (see Figs. 1, 2).

ERGs were performed using Burian-Allen contact lens electrodes referred to the outer canthi of each eye. Scotopic responses were tested using a Ganzfield stimulus of 28 Foot Lamberts after 20 minutes of dark adaptation. Photopic responses were obtained with 30 Foot Lambert background illumination and 28 Foot Lambert stimulus intensity. Thirty-hertz cone responses were obtained using an intensity of 4 Foot Lamberts against a background of 10 Foot Lamberts. Responses were obtained using a Nicolet CA1000 clinical averager. Frequency bandpass filtering was set at $1-1000 \mathrm{~Hz}$, except when recording oscillatory potentials, when the band-pass was set at 100-1000 $\mathrm{Hz}$. Three averages were obtained for scotopic stimuli and 20 for photopic and $30 \mathrm{~Hz}$ stimuli.

As this was a study over 8 years, only two of the more recently examined patients had PERGs. These were recorded using gold foil electrodes referred to the ipsilateral outer canthus. The stimulus consisted of a 50 minute checkerboard reversing at $5.9 \mathrm{~Hz}$. The responses were averaged 150 times and repeated three times, using an artefact rejection of $50 \mu \mathrm{V}$ and a band-pass of $1-100 \mathrm{~Hz}$.

Statistical analysis of results was done using the paired $t$-test for comparisons of findings in those patients assessed both acutely and at 6 month followup $(n=7)$ and using analysis of variance with Bonferroni's procedure for comparisons of findings between controls, acute patients and long-term postacute patients without acute data. Figures from individual eyes were used for calculations.

\section{RESULTS}

Visual Acuity

At presentation 22 eyes $(22 / 68,32 \%)$ had a best corrected visual acuity of $\leqslant 6 / 12$. At follow-up 10 eyes $(10 / 58,17 \%)$ had visual acuities of $\leqslant 6 / 12$. The separate figures for the patients seen at 6 month follow-up and those with 2-4 years of follow-up are given in Table I. The long-term causes of decreased visual acuity were: anterior ischaemic optic neuropathy (3), including one which developed after starting treatment), continuing macular exudates (4), branch vein occlusion (1), cataract (1) and atrophic depigmented area of macula (1).

\section{Fundal Appearance}

At presentation 34 eyes $(34 / 68,50 \%)$ had grade IV retinopathy and 34 had grade III. At follow-up (those seen at 6 months and those seen at 2-4 years), no eyes had grade IV retinopathy, 9 eyes (9/58, $15.5 \%$ ) had grade III, $38(65.5 \%)$ had grade II and 11 $(19 \%)$ had grade I. Exudates were present in 6 eyes of those with grade III retinopathy; cotton wool spots and small retinal haemorrhages were present in 3 . Other findings were optic atrophy (3), branch retinal vein occlusion (1) and areas of depigmented retina (6). No fundi could be classified as normal, i.e. without a hypertensive grading. Separate figures for the 7 patients seen acutely and followed up at 6 months are given in Table II.

Table I. Visual acuity at presentation and at follow-up (\% of all eyes)

\begin{tabular}{lllllllll}
\hline & \multicolumn{7}{c}{ Visual acuity } \\
\cline { 2 - 8 } & $\leqslant 6 / 6$ & $6 / 9$ & $6 / 12$ & $6 / 18$ & $6 / 24$ & $6 / 36$ & $\geqslant 6 / 60$ \\
\hline Totals & & & & & & & \\
$\quad$ Presentation (68 eyes) & 41 & 27 & 7.3 & 6 & 4 & 7.3 & 7.3 \\
$\quad$ Follow-up (58 eyes) & 53.5 & 29 & 7 & 1.7 & 1.7 & 0 & 7 \\
6 month follow-up & & & & & & & \\
$\quad$ Presentation (14 eyes) & 36 & 29 & 0 & 7 & 7 & 7 & 14 \\
$\quad$ Follow-up (14 eyes) & 50 & 29 & 7 & 0 & 0 & 0 & 14 \\
2-4 year follow-up & & & & & & & \\
Presentation (44 eyes) & 50 & 25 & 7 & 7 & 2 & 4.5 & 4.5 \\
$\quad$ Follow-up (44 eyes) & 52 & 29.5 & 9 & 2 & 2 & 0 & 4.5 \\
\hline
\end{tabular}


Table II. Data on the 7 patients in whom pattern VEP and ERG recordings were made acutely and up to 6 months later

\begin{tabular}{|c|c|c|c|c|c|c|c|c|c|c|c|c|c|c|c|}
\hline \multirow[b]{3}{*}{ Patient } & \multirow{3}{*}{$\begin{array}{l}\text { Length of } \\
\text { follow-up } \\
\text { (months) }\end{array}$} & \multicolumn{4}{|c|}{ VEP } & \multicolumn{4}{|c|}{ Cone ERG } & \multirow{2}{*}{\multicolumn{2}{|c|}{ Hypertensive grading }} & \multirow{2}{*}{\multicolumn{2}{|c|}{ Acuity }} & \multirow{2}{*}{\multicolumn{2}{|c|}{ Fields $^{\mathrm{a}}$}} \\
\hline & & \multicolumn{2}{|c|}{ Amplitude $(\mu \mathrm{V})$} & \multicolumn{2}{|c|}{ Latency $(\mathrm{ms})$} & \multicolumn{2}{|c|}{ Amplitude $(\mu \mathrm{V})$} & \multicolumn{2}{|c|}{ Latency $(\mathrm{ms})$} & & & & & & \\
\hline & & $\mathrm{R}$ & $\mathrm{L}$ & $\mathrm{R}$ & $\mathrm{L}$ & $\mathrm{R}$ & $\mathrm{L}$ & $\mathrm{R}$ & $\mathrm{L}$ & $\mathrm{R}$ & $\mathrm{L}$ & $\mathrm{R}$ & $\mathrm{L}$ & $\mathrm{R}$ & $\mathrm{L}$ \\
\hline \multirow[t]{2}{*}{1} & & 2 & 3 & 148 & 137 & 12 & 18 & 31 & 28 & IV & IV & $6 / 24$ & $6 / 60$ & 3 & 4 \\
\hline & 4 & 6 & 4 & 126 & 116 & 14 & 22 & 33 & 28 & III & III & $6 / 9$ & $6 / 18$ & 2 & 4 \\
\hline \multirow{2}{*}{2} & & 2 & 5 & 118 & 100 & 46 & 72 & 33 & 28 & IV & III & $6 / 18$ & $6 / 9$ & 3,2 & 2 \\
\hline & 6 & 4 & 5 & 107 & 100 & 38 & 59 & 34 & 30 & II & $I I$ & $6 / 9$ & $6 / 5$ & 2 & 1 \\
\hline \multirow[t]{2}{*}{3} & & 6 & 5 & 118 & 109 & 53 & 49 & 30 & 27 & III & III & $6 / 6$ & $6 / 5$ & 1 & 1 \\
\hline & 5 & 8 & 9 & 108 & 100 & 58 & 63 & 31 & 28 & $I I$ & $I I$ & $6 / 5$ & $6 / 5$ & 1 & 1 \\
\hline \multirow[t]{2}{*}{4} & & 6 & 1 & 114 & 150 & 48 & 22 & 26 & 28 & III & IV & $6 / 5$ & $2 / 60$ & 2 & 5 \\
\hline & 5 & 6 & 4 & 108 & 118 & 50 & 20 & 25 & 28 & II & $O A$ & $6 / 5$ & $2 / 60$ & 2 & 5 \\
\hline \multirow[t]{2}{*}{5} & & 3 & 2 & 120 & 157 & 51 & 40 & 29 & 30 & IV & IV & $6 / 9$ & $6 / 36$ & 1 & 5 \\
\hline & 5 & 5 & 3 & 109 & 126 & 4.3 & 29 & 29 & 31 & $I I$ & $O A$ & $6 / 9$ & $H M$ & 1 & 5 \\
\hline \multirow[t]{2}{*}{6} & & 2 & 2 & 126 & 134 & 53 & 43 & 29 & 27 & IV & IV & $6 / 9$ & $6 / 9$ & 3,5 & 2,4 \\
\hline & 5 & 2 & 2 & 110 & 120 & 73 & 68 & 28 & 26 & $I I$ & II & $6 / 5$ & $6 / 5$ & 5 & 4 \\
\hline \multirow[t]{2}{*}{7} & & 3 & 4 & 117 & 97 & 24 & 24 & 30 & 27 & III & III & $6 / 5$ & $6 / 5$ & 2 & 1 \\
\hline & 5 & 5 & 5 & 100 & 100 & 27 & 28 & 30 & 27 & $I I$ & $I I$ & $6 / 5$ & $6 / 5$ & 1 & 1 \\
\hline
\end{tabular}

Figures in italics indicate follow-up data.

$\mathrm{OA}$, optic atrophy.

${ }^{\mathrm{a}}$, normal field; 2 , enlarged blind spot; 3 , centro-caecal scotoma; 4. quadrantinopia; 5, altitudinal field defect.

\section{Visual Fields}

In the acute group visual field abnormalities occurred in 10 of the 12 patients ( 18 eyes, $75 \%$ ). These defects were: altitudinal ( 9 eyes), enlarged blind spots (10 eyes), arcuate scotomas ( 7 eyes) and centrocaecal scotoma ( 8 eyes) (some eyes had more than one pattern of field defect). In the 7 patients followed up, 6 patients (10 eyes) still had field defects of which 6 eyes were improved but only 2 to within normal limits (Table II). Of the 22 patients assessed after $2-4$ years, field defects were found in 5 patients ( 7 eyes, $16 \%$ ). The 3 patients with optic atrophy all had inferior altitudinal defects, but 1 also had an enlarged blind spot and an accurate defect.

\section{$E R G$}

All 12 of the patients measured acutely had abnormalities of the ERG compared with controls (Table III). Unilateral delay of the scotopic $b$ wave in combination with a reduction and delay of the oscillatory potentials occurred in all 12 patients, in 4 cases in both eyes. Four patients (33\%) also had a unilateral reduction in amplitude of the scotopic $b$ wave. Unilateral delay of the photopic and cone (30 $\mathrm{Hz}$ ) b wave also occurred in all 12 patients. In 5 cases this was bilateral. Seven patients $(58 \%)$ had a reduction in amplitude of the cone $b$ wave in the worse affected eye. Two patients revealed a reduction of the scotopic b wave $>2.5$ standard deviations below the absolute limits of normal for this laboratory (lower limits: $280 \mu \mathrm{V}$ scotopic; $40 \mu \mathrm{V}$ photopic; $25 \mu \mathrm{V}$ cone $30 \mathrm{~Hz}$ ).

In the 7 patients who were followed up within 6 months of the acute episode there was no significant difference in the mean ERG amplitude and latency compared with the acute recordings (Tables II, IV), none of the ERGs having changed significantly in any of the patients.

In the group assessed after 2-4 years ERG b wave abnormalities occurred in 18 of 22 patients ( $75 \%$ ), all 18 having at least a unilateral delay of the scotopic (23 eyes), photopic (24 eyes) and cone $(30 \mathrm{~Hz})$ responses (28 eyes), with 6 of these ( 8 eyes) also having a reduction in amplitude of the cone $(30 \mathrm{~Hz})$ response and 3 ( 3 eyes) a reduction in amplitude of the scotopic b wave. Oscillatory potentials were reduced in 26 eyes (Table V). One patient had a reduction of the scotopic b wave $>2.5$ standard deviations below the absolute limits of normal.

In the 2 patients measured acutely who underwent PERG, N95 was reduced in both ( 3 eyes) and P50 was reduced in one (1 eye). The P50/N95 ratio was abnormally high in the 3 eyes with reduced N95. In

Table III. Mean pattern VEP and ERG amplitudes and latencies in all 12 patients measured acutely, and in the group assessed 2-4 years later, compared with controls (standard errors in parentheses)

\begin{tabular}{|c|c|c|c|c|c|}
\hline Parameter & Control & & ute & $2-4$ yea & rs post-acute \\
\hline VEP amplitude $(\mu \mathrm{V})$ & $8.62(0.77)$ & 4.15 & $(0.37)^{* * * *}$ & 7.26 & $(0.53)^{*}$ \\
\hline VEP latency (ms) & $106.6 \quad(1.24)$ & 128.9 & $(2.16) * * *$ & 109.1 & $(1.33)^{\mathrm{NS}}$ \\
\hline ERG scotopic b wave amplitude $(\mu \mathrm{V})$ & $387.4 \quad(3.94)$ & 312.6 & $(4.28) * * *$ & 338.7 & $(3.68)^{* * *}$ \\
\hline ERG scotopic b wave latency (ms) & $41.2 \quad(1.43)$ & 48.4 & $(2.16)^{* * *}$ & 45.0 & $(1.62)^{* *}$ \\
\hline ERG cone b wave amplitude $(\mu \mathrm{V})$ & $67.5 \quad(5.16)$ & 44.9 & $(3.57)^{* * *}$ & 51.4 & $(4.55)^{* * *}$ \\
\hline ERG cone b wave latency (ms) & $26.8 \quad(0.41)$ & 30.0 & $(0.55)^{* * *}$ & 29.4 & $(0.49)^{* *}$ \\
\hline
\end{tabular}

*p<0.05 compared with controls; $* * p<0.01$ compared with controls: $* * * p<0.005$ compared with controls; ${ }^{\text {NS }}$ no significant difference compared with controls. 
Table IV. Mean pattern VEP and cone ERG $(30 \mathrm{~Hz})$ amplitudes and latencies in the 7 patients measured acutely and up to 6 months later (standard errors in parentheses)

\begin{tabular}{|c|c|c|c|}
\hline Stimulus parameter & Acute & Post-acute & Significance \\
\hline VEP amplitude $(\mu \mathrm{V})$ & $3.3 \quad(0.44)$ & $4.9 \quad(0.58)$ & $p<0.025$ \\
\hline VEP latency (ms) & $123.8 \quad(4.89)$ & $110.9 \quad(4.16)$ & $p<0.005$ \\
\hline ERG cone b wave amplitude $(\mu \mathrm{V})$ & $39.6 \quad(4.54)$ & $42.3 \quad(5.23)$ & NS \\
\hline ERG cone b wave latency (ms) & $29.0 \quad(0.60)$ & $28.3 \quad(0.53)$ & NS \\
\hline
\end{tabular}

NS, not significant.

both patients the PERG abnormality was associated with an abnormal VEP, and in one eye the ERG was normal.

\section{$V E P$}

Of the 12 patients measured acutely, $11(92 \%)(17 /$ $24,70 \%$ eyes) had abnormal pattern VEPs, $10(83 \%)$ $(14 / 24,58 \%$ eyes) exhibiting reductions in amplitude, and in 15 eyes $(62.5 \%)$ of 9 of these patients the VEPs were delayed beyond the normal limit of P100 latency of $122 \mathrm{~ms}$ (normal limit for this laboratory). In 5 cases these changes were unilateral, correlating with the severity or presence of disc swelling. The group mean latency of the P100 component in all 24 eyes was $128.9 \mathrm{~ms}$. The group mean amplitude was $4.1 \mu \mathrm{V}$. Of the 7 patients followed up, 6 eyes had a delay of the P100 beyond 122 ms (group mean 123.8 $\mathrm{ms}$ ) during the acute phase; 4 recovered to within normal limits (group mean $110.9 \mathrm{~ms}$ ), demonstrating significant improvement $(p<0.005)$. In this group of 7 patients the amplitude was reduced in 9 eyes acutely (group mean $3.3 \mu \mathrm{V}$ ). In 6 this significantly recovered (group mean $4.9 \mu \mathrm{V})(p<0.025)$. A bifid (PNP) wave form (P135) occurred in 13 of the 24 eyes seen acutely (Figs. 1,2); 8 of these were in the 7 patients (14 eyes) followed up. At follow-up the pattern of response had returned to normal in 6 of these 8 eyes. In the group measured at $2-4$ years only 2 VEPs were abnormal (2 eyes; 2/44, 0.045\%), 1 reduced and delayed, 1 reduced only (group mean latency $109.1 \mathrm{~ms}$ ), which was significantly different from the patients measured acutely $(p<0.005)$. The group mean P100 amplitude was $7.2 \mu \mathrm{V}$, which was significantly greater than that measured acutely $(p<0.005)$. Three of the 12 patients measured acutely, with unilateral ERG abnormalities and unilateral VEP abnormalities, exhibited VEP abnormalities in the eye with a normal ERG (Figs. 3, 4).
Causes of the Accelerated Hypertension, the Effectiveness of Hypertensive Treatment and Other Systemic Features

In 6 cases, renal disease was found to be the cause of the accelerated hypertension. In 22 of 28 (78\%) the creatinine concentration was found to be higher than normal $(>120 \mathrm{mmol} / \mathrm{l})$ at presentation. One patient had toxaemia of pregnancy. The remainder (27) were classified as essential hypertension. In the group followed up for 2-4 years after presentation 11 of 22 $(50 \%)$ still had diastolic blood pressures $\geqslant 100$ $\mathrm{mmHg}$. This is despite extensive efforts at treatment. These included 3 of the patients with continued macular exudates. Chest radiographs showed left ventricular hypertrophy in 11 of $28(39 \%)$ cases. Electrocardiograms showed left ventricular hypertrophy in 13 of $27(48 \%)$ cases and evidence of ischaemic heart disease in 14 of $27(52 \%)$ cases. During follow-up an additional 4 patients suffered from renal disease, 8 from symptoms of ischaemic heart disease, and 4 had a cerebrovascular event.

\section{DISCUSSION}

Accelerated hypertension can affect the fundus in three main ways: by causing a retinopathy, choroidopathy and an optic neuropathy. ${ }^{19,20}$ The clinical presentation of these features varies greatly from patient to patient, presumably reflecting such factors as the severity of the hypertension, varying ability to resist its effects and the speed of onset of the hypertension, as well as coexistent disease such as diabetes. For example, hypertensive retinopathy occurs earlier than choroidopathy or optic neuropathy. ${ }^{20}$ Choroidopathy tends to occur in the relatively young, especially with acute hypertension - for example, in toxaemia of pregnancy. ${ }^{23}$

Whether visual acuity will be reduced depends on whether the macular or optic nerve function is affected. Florid cases can have surprisingly good

Table V. Mean pattern VEP and ERG amplitudes and latencies in all 12 patients recorded during the acute phase of accelerated hypertension, compared with recordings made 2-4 years after the acute episode (standard errors in parentheses)

\begin{tabular}{|c|c|c|c|}
\hline Parameter & Acute & 2-4 years post-acute & Significance \\
\hline$\overline{\text { VEP amplitude }(\mu \mathrm{V})}$ & $4.1 \quad(0.37)$ & $7.26(0.53)$ & $p<0.005$ \\
\hline VEP latency $(\mathrm{ms})$ & $128.9 \quad(2.16)$ & $109.1 \quad(1.33)$ & $p<0.005$ \\
\hline ERG scotopic b wave amplitude $(\mu \mathrm{V})$ & $312.6 \quad(4.28)$ & $338.7 \quad(3.68)$ & $p<0.01$ \\
\hline ERG cone $b$ wave amplitude $(\mu \mathrm{V})$ & $44.9 \quad(3.67)$ & $51.4(4.55)$ & NS \\
\hline ERG cone b wave latency (ms) & $30.0 \quad(0.55)$ & $29.1 \quad(0.49)$ & NS \\
\hline
\end{tabular}




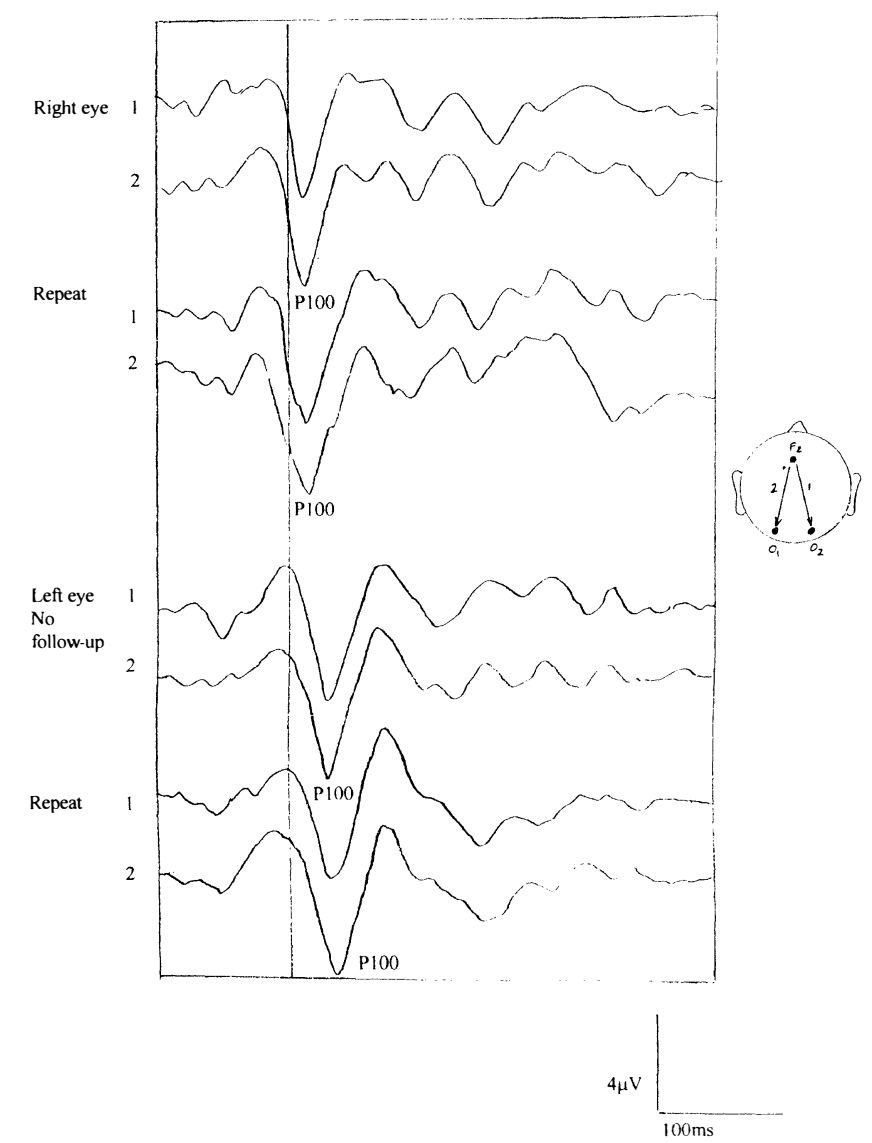

Fig. 3. Female, aged 35 years. During the acute phase this patient had left disc swelling and a right central retinal vein occlusion. The VEP was delayed in the left eye only. The ERG of this patient is shown in Fig. 4. This was normal in the left eye but abnormal in the right. The patient was not followed up.

vision, though, as can be seen from our results, several did have reduced visual acuity at initial presentation $(22 / 68,32 \%$ of eyes). The severity of these changes were usually asymmetric. The visual acuity remained reduced in 7 of $44(16 \%)$ eyes seen 2-4 years after the acute episode.

The ERG was at least unilaterally abnormal in all the cases measured acutely. The abnormal Ganzfeld ERG recordings suggest widespread retinal damage. However, none of the ERGs was severely reduced and changes mainly affected the cone system. The ERG remained abnormal in all these cases and in $82 \%$ of the cases seen between 2 and 4 years after the acute episode. This is despite resolution of the majority of the fundal signs. This is not surprising considering that some of the features of the retinopathy and choroidopathy may involve infarction of tissue.

The pattern VEP was abnormal in the majority of the acute cases studied ( $92 \%$ ), being delayed in 15 eyes $(62.5 \%)$ and with 14 eyes $(58 \%)$ having a decrease in amplitude. It is difficult to ascertain how much of this was due to macular pathology as opposed to decreased optic nerve function. Most of
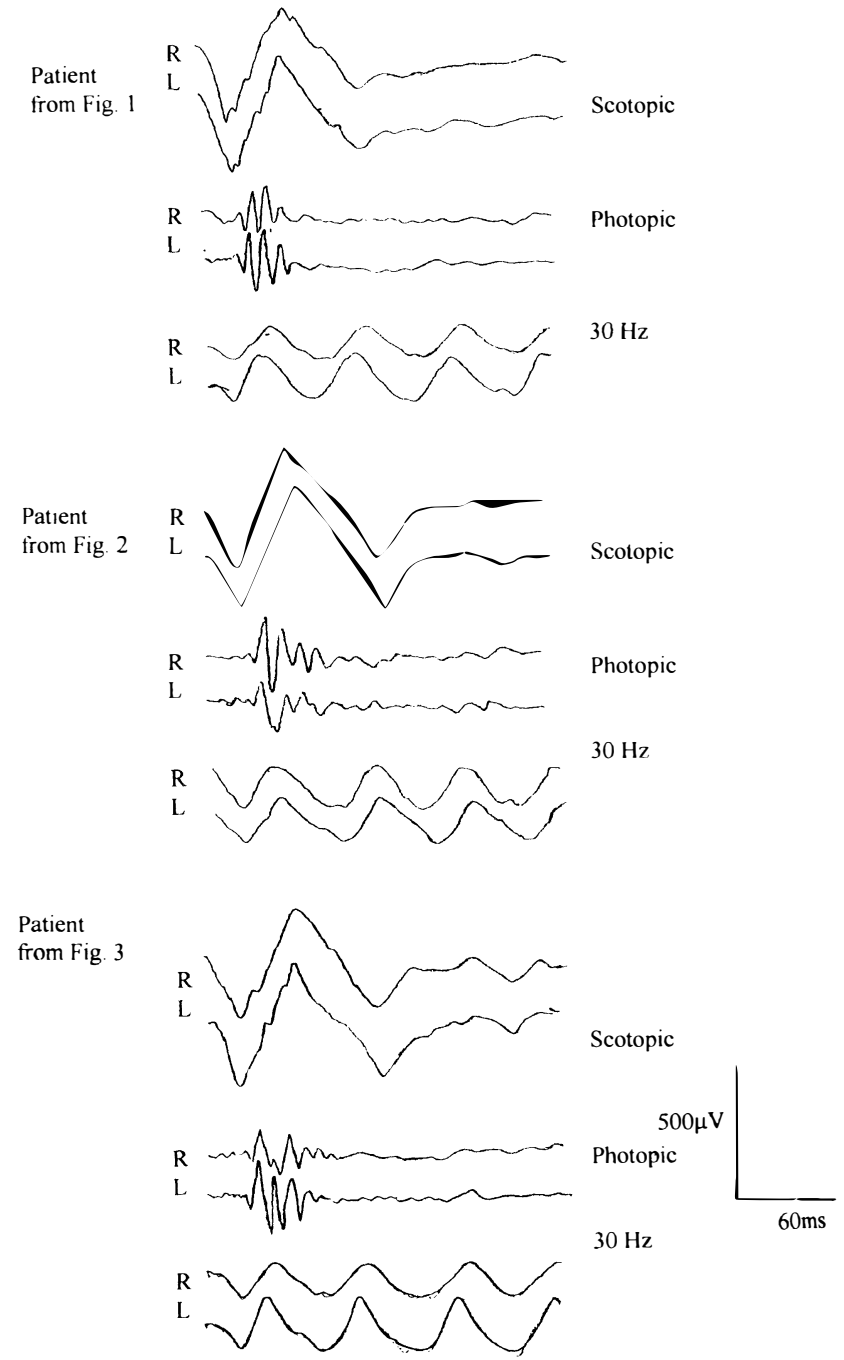

Fig. 4. The ERGs of the patients in Figs. 1, 2 and 3.

the patients underwent electrophysiological testingbefore PERG was available in our laboratory. ${ }^{24}$ Clinically both the macula and the optic nerve are affected in accelerated hypertension. We would argue, however, that a major factor is optic nerve ischaemia. In the 2 patients who underwent PERG the P50/N95 ratio was higher than normal, implying an optic neuropathy rather than maculopathy, although P50 was reduced in one eye suggesting some macular involvement. It was also notable that in 3 patients with unilateral ERG and VEP abnormalities the VEP was abnormal, with a PNP appearance in the eye with the normal ERG. A PNP wave form, previously described with AION (see Methods), was seen in 16 of 24 eyes seen acutely.

The 3 patients with optic atrophy had altitudinal defects compatible with the diagnosis of AION. Many of the other field defects were also compatible with a decrease in optic nerve function. However, the optic disc pallor may have reflected either retinal nerve fibre and ganglion cell loss in the retina, or primary optic disc damage at the retrolaminar level.

Pathologically optic disc oedema represents nerve 
fibre swelling and is thought to occur due to ischaemia interfering with axoplasmic flow in the nerve head. ${ }^{25}$ Hayreh et al. ${ }^{21}$ in their experiments on rhesus monkeys, concluded that optic disc oedema in accelerated hypertension represents an ischaemic optic neuropathy. Unlike the ERG recordings, the VEP tends to return to normal in line with the resolution of the disc swelling. This could suggest reversibility of the ischaemic optic neuropathy, although in 3 cases severe optic atrophy remained. Reversible optic disc ischaemia has been noted before, as it is thought to occur in young diabetics who develop transient optic disc oedema.

Non-arteritic AION usually does not occur in the context of accelerated hypertension, but rather in patients with diabetes or atherosclerosis, ${ }^{26}$ though hypertension has been associated as a risk factor in some studies. ${ }^{27}$ Some authors argue that certain cases of ischaemic optic neuropathy may be specifically due to hypertensive optic nerve infarction. ${ }^{28}$ This paper supports the theory that hypertension can cause anterior ischaemic optic neuropathy.

In conclusion we suggest that during the acute stage of accelerated hypertension there is a high incidence of ischaemic optic neuropathy which usually resolves, but in a few cases AION ensues. This was the cause for the poorest visual outcome. Permanent retinal damage is also evident.

Key words: Accelerated. malignant hypertension. Visual evoked potential, Optic neuropathy.

\section{REFERENCES}

1. Bright R. Cases and observations, illustrative of renal disease accompanied with the secretion of albuminous urine. Guys Hosp Rep 1836;1:338-400.

2. Mackenzie. Amaurosis from fatty degeneration of the retina, originating in Bright's disease. R Lond Ophthalmic Hosp Rep 1860;2:181-5.

3. Duke-Elder WS (ed). Textbook of ophthalmology, vol III. London: H. Kimpton, 1940;2676.

4. Leibreich R. Ophthalmoskopischer Bejund bin Morbus Brightii. Graefes Arch Clin Exp Ophthalmol 1859;5: 265-8.

5. Riva-Rocci S. Gazz med di Torino 1896;47:981.

6. Volhard F, Fahr KT. Die Brightsche Nierenkrankheit; Klinik, Pathologie und Atlas. Berlin: Springer, 1914.

7. Keith NM, Wagener HP, Barker NW. Some different types of essential hypertension: their course and prognosis. Am J Med Sci 1939;197:332-43.

8. Bulpitt CJ. Prognosis of treated hypertension 19511981. Br J Clin Pharmacol 1982;13:73-9.

9. Walsh JB. Hypertensive retinopathy: description, classification and prognosis. Ophthalmology 1982;89: 1127-31.

10. Ahmed MEK, Walker JM, Beevers DG, Beevers M.
Lack of difference between malignant and accelerated hypertension. BMJ 1986;292:235-7.

11. McGregor E, Isles CG, Jay JL, Lever AF, Murray GD. Retinal changes in malignant hypertension. BMJ 1986;292:233-4.

12. World Health Organization. Arterial hypertension. WHO Tech Rep Ser 1978;628:57.

13. Eames SM, Beevers DG, Dodson PM. Hypertension and the retina. In: Dodson PM, Gibson JM, Kritzinger EE, editors. Clinical retinopathies. London: Chapman Hall, 1995.

14. Breckenbridge A, Dollery CT, Parry EHO. Prognosis of treated hypertension: changes in life expectancy and cause of death between 1952 and 1967. Q J Med 1970;39:411-29.

15. Gudbransson T, Hansson L, Herlitz H, Andren L. Malignant hypertension: improving prognosis in a rare disease. Acta Med Scand 1979;206:495-9.

16. Lowenstein J. The effects of treatment on target organ damage in hypertensive disease. Postgrad Med J 1985;61:773-8.

17. Bock KD. Regression of retinal vascular changes by antihypertensive therapy. Hypertension 1984;6: $158-62$.

18. Tso MOM, Jampol LM. Pathophysiology of hypertensive retinopathy. Ophthalmology 1982;89:1132-45.

19. Tso MOM, Jampol LM. Hypertensive retinopathy, choroidopathy and optic neuropathy of hypertensive disease. In: Laragh JH, Brenner BM, editors. Hypertension: pathophysiology, diagnosis and management. New York: Raven Press, 1990:433-65.

20. Hayreh SS, Servais GE, Virdi PS, Marcus ML, Rojas P, Woolson RF. Fundus lesions in malignant hypertension. III. Arterial blood pressure, biochemical and fundus changes. Ophthalmology 1986;93:45-59.

21. Hayreh SS, Servais GE, Virdi PS. Fundus lesions in malignant hypertension. V. Hypertensive optic neuropathy. Ophthalmology 1986;93:74-87.

22. Thompson PD, Mastaglia FL, Carroll WM. Anterior ischaemic optic neuropathy: a correlative clinical and visual evoked potential study of 18 patients. 1986;49:128-35.

23. Fastenberg DM, Fetkenhour CL, Choromokos E, Shoch DE. Choroidal vascular changes in toxemia of pregnancy. Am J Ophthalmol 1980;89:362-8.

24. Carr RE, Siegel IM. Electrodiagnostic testing of the visual system: a clinical guide. Philadelphia: FA Davis, 1990.

25. Garner A, Ashton N. Pathogenesis of hypertensive retinopathy: a review. J R Soc Med 1979;72:362-5.

26. Talks SJ, Chong NHV, Gibson JM, Dodson PM. Fibrinogen, cholesterol and smoking as risk factors for non-arteritic anterior ischaemic optic neuropathy. Eye 1995;9:85-8.

27. Guyer DR, Miller NR, Auer CL, Fine SL. The risk of cerebrovascular and cardiovascular disease in patients with anterior ischaemic optic neuropathy. Arch Ophthalmol 1985;103:1136-42.

28. Smith JL, Goldhammer Y. Hypertensive optic neuropathy. Trans Am Acad Ophthalmol Otolaryngol 1974;79:520-3. 